\title{
Fecal biomarkers of intestinal health and disease in children
}

\author{
Tamara Pang ${ }^{1}$, Steven T. Leach ${ }^{1,2}$, Tamarah Katz ${ }^{3}$, Andrew S. Day ${ }^{4}$ and Chee Y. Ooi ${ }^{1,2}{ }^{*}$ \\ ${ }^{\prime}$ Faculty of Medicine, School of Women's and Children's Health, University of New South Wales, Sydney, NSW, Australia \\ ${ }^{2}$ Department of Gastroenterology, Sydney Children's Hospital Randwick, Sydney, NSW, Australia \\ ${ }^{3}$ Department of Nutrition and Dietetics, Sydney Children's Hospital, Sydney, NSW, Australia \\ ${ }^{4}$ Department of Paediatrics, University of Otago, Christchurch, New Zealand
}

Edited by:

Kevan Jacobson, British Columbia

Children's Hospital, Canada

Reviewed by:

Marco Manfredi, Azienda

Ospedaliero-Universitaria Parma, Italy

Eytan Wine, University of Alberta,

Canada

\section{*Correspondence:}

Chee Y. Ooi, Discipline of Paediatrics,

School of Women's and Children's

Health, Sydney Children's Hospital,

High Street, Randwick, NSW 2031,

Australia

e-mail:keith.ooi@unsw.edu.au
The identification of various fecal biomarkers has provided insight into the intestinal milieu. Most of these markers are associated with the innate immune system of the gut, apart from the more novel M2-pyruvate kinase. The innate immunity of the gut plays a role in maintaining a fine balance between tolerance to commensal bacteria and immune response to potential pathogens. It is a complex system, which comprises of multiple elements, including antimicrobial peptides (e.g., defensins, cathelicidins, lactoferrin, and osteoprotegerin), inflammatory proteins (e.g., calprotectin and S100A12), and microbial products (e.g., short-chain fatty acids). Dysfunction of any component can lead to the development of intestinal disease, and different diseases have been associated with different fecal levels of these biomarkers. Each fecal biomarker provides information on specific biological and disease processes. Therefore, stool quantification of these biomarkers provides a noninvasive method to define potential pathways behind the pathogenesis of diseases and can assist in the assessment and diagnosis of various gastrointestinal conditions. The abovementioned fecal biomarkers and their role in intestinal health and disease will be reviewed in this paper with a pediatric focus.

Keywords: inflammation, defensins, cathelicidins, lactoferrin, osteoprotegerin, calprotectin, S100A12, M2-pyruvate kinase

\section{INTRODUCTION}

The innate immune system of the gut comprises of multiple elements (Table 1), each of which contributes to the fine balance between tolerance to commensal bacteria and response to potential pathogens (1). The gastrointestinal epithelium in particular, is constantly exposed to a large amount of intestinal microflora yet is able to maintain a physical barrier to exogenous stimuli while allowing the selective entry of essential nutrients (2). Its mucosal surface is covered by a mucus layer, which contains various antimicrobial peptides (AMPs) such as osteoprotegerin (OPG), defensins, and cathelicidins as well as commensal microbiota, together forming the first line of defense against pathogens. Should this mucosal barrier be breached, circulating immune cells like neutrophils and macrophages provide a second source of protection via inflammatory proteins such as lactoferrin and S100 proteins (2).

One mechanism through which the intestinal microbiota plays a crucial role in intestinal innate immune defense is via the production of short-chain fatty acids when colonic bacteria ferment carbohydrates (3).

Therefore, dysfunction of any of these components of the innate immune system can lead to impairment of the host's mucosal defenses (4), alterations in intestinal microbial composition, and increase in the frequency and severity of intestinal infections. It has been widely hypothesized that this resultant dysbiosis can lead to gradual bacterial invasion, inflammation, and a loss of tolerance to gut bacteria (5) (Figure 1). There is abundant evidence that dysbiosis may have multiple effects on the physiology and immunology of the host, and has been associated with the development of a variety of diseases including atopy (6), obesity (7), types I and II diabetes $(8,9)$, cardiovascular disease (10), and inflammatory disorders $(11,12)$.

The identification of various intestinal AMPs, inflammatory proteins, and bacterial products has provided investigators potential insight into the intestinal milieu using non-invasive methods such as stool quantification. Understanding the role of these biomarkers in healthy (Table 2) and disease states may help characterize pathways behind disease pathogenesis, and in turn guide the development of prospective therapies.

Many fecal biomarkers have been identified to date but only a few have been more extensively studied in children. Hence in this review, we aim to provide an overview of the roles of defensins, cathelicidins, lactoferrin, OPG, S100 proteins, SCFA, and the more novel M2-pyruvate kinase (M2-PK) in health and various disease states in the pediatric population. The practical aspects and limitations of fecal biomarkers are also discussed. We performed a search of the databases Medline, EMBASE, and PubMed for articles written in English, including review articles, related to the relevant fecal biomarkers in children, published after the year 1980 .

\section{DEFENSINS}

Defensins are AMPs that are divided into two main subfamilies based on structure: $\alpha$ - and $\beta$-defensins (4). To date, 10 human 
defensins have been identified (5), further details of which are discussed in Table 2.

\section{ROLE IN HEALTH}

As AMPs, defensins exhibit microbiocidal activity by forming micropores in the membrane, causing loss of structural integrity and eventually cell lysis (13). Via this mechanism, defensins are microbiocidal against Gram-positive and Gram-negative bacteria, fungi, viruses, and protozoa (14) thereby protecting the intestinal

Table 1 | Components of the intestinal innate immune system.

\begin{tabular}{ll}
\hline Mechanical barriers & Mucous layer (2) \\
& Intestinal epithelial cell layer (4) \\
& Intestinal motility (4) \\
& Defensins \\
& Cathelicidins \\
Antimicrobial peptides & Osteoprotegerin \\
& Lactoferrin \\
& Lysozyme (1) \\
& Secretory phospholipase A2 (1) \\
& Angiogenins (4) \\
& Calprotectin (S100A8/S100A9) \\
& S100A12 \\
Inflammatory proteins & Intestinal microflora (4) \\
Short-chain fatty acids \\
products
\end{tabular}

epithelium and stem cells from pathogens as well as regulating the number and composition of commensal bacteria (5).

\section{$\alpha$-Defensins}

The microbiocidal activity of $\alpha$-defensins was demonstrated in a cohort study of African adults, which showed that low Paneth cell $\alpha$-defensin-gene expression was associated with a higher risk of diarrheal infections (15). Interestingly, although human $\alpha$ defensins (HD) 5 and 6 are largely confined to the small intestine, they are also secreted in the colon of patients with ulcerative colitis (UC) due to the presence of metaplastic Paneth cells. This is thought to provide an alternative "on-demand" mechanism that provides antimicrobial expression and protection of the gut (14).

Apart from their microbiocidal role in the innate immune system, $\alpha$-defensins are chemotactic for monocytes, dendritic, and $\mathrm{T}$ cells, thereby providing regulation of adaptive immunity via activation and recruitment of adaptive immune cells (4). Furthermore, $\alpha$-defensins $1-4$, known also as human neutrophil peptides (HNPs), enhance the expression of TNF- $\alpha$ and IL- $1 \beta$ in activated human monocytes and reduce the expression of vascular cell adhesion molecule (VCAM)-1 in human endothelial cells activated by TNF- $\alpha$. This regulation of cytokine production and adhesion molecule expression indicates a potential role of HNPs in modulating inflammatory responses (16).

\section{$\beta$-Defensins}

The antimicrobial function of $\beta$-defensins has also been well established. During health, the constitutive expression of human $\beta$-defensin (HBD) 1 by epithelial cells prevents microbial invasion by strengthening the intestinal mucosal barrier. The induction of HBD2, 3, and 4 during inflammation or infection may prevent further bacterial entry into an already compromised epithelium and contribute to antimicrobial defense during inflammation

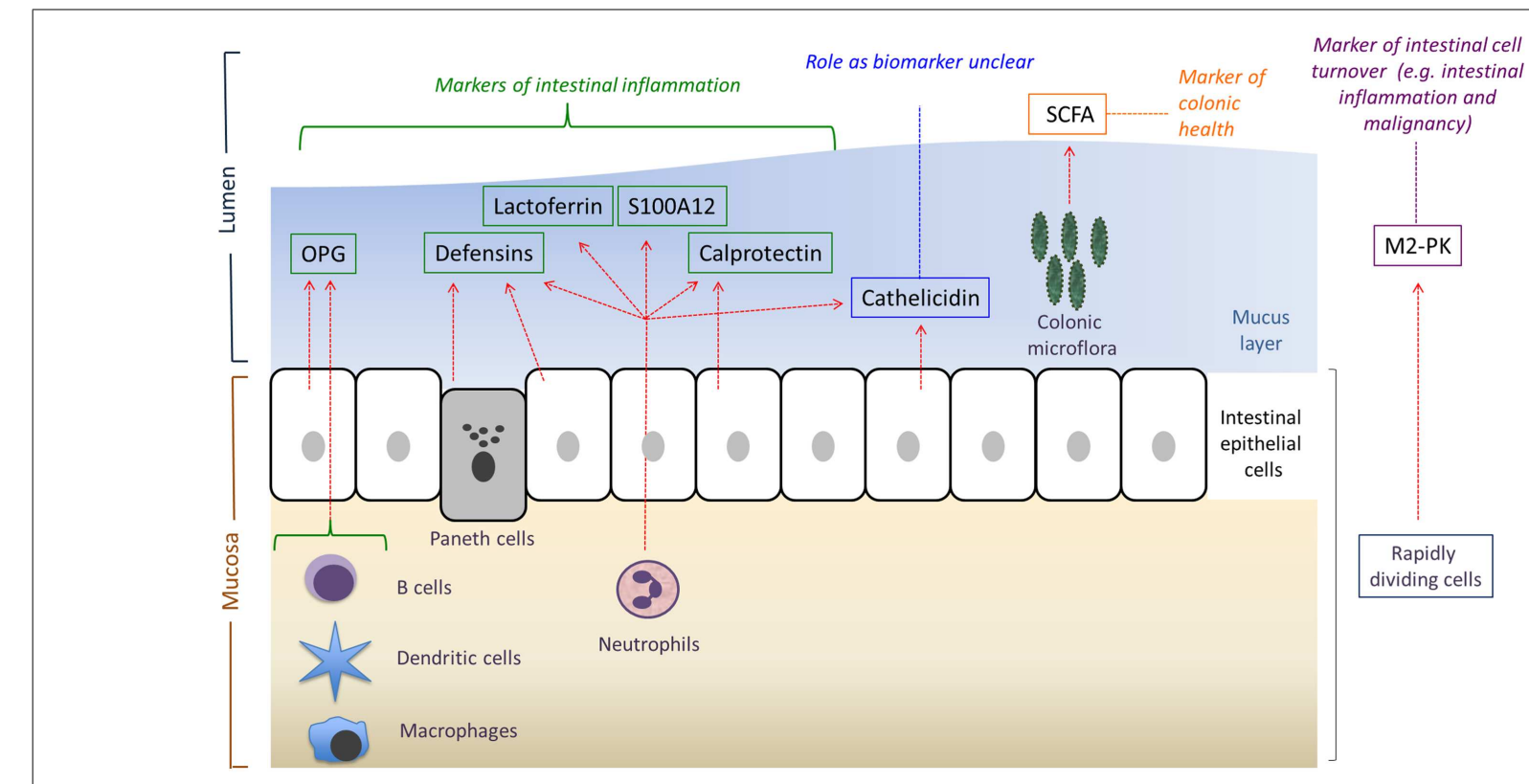

FIGURE 1 | An overview of the main sources and potential uses of the various fecal biomarkers reviewed in this article. OPG, osteoprotegerin; SCFA, short-chain fatty acids; M2-PK, M2-pyruvate kinase. Adapted from Ref. (12). 
Table 2 |The expression and function of defensins, cathelicidins, lactoferrin, OPG, S100 proteins, M2-pyruvate kinase (M2-PK), and short-chain fatty acids (SCFA).

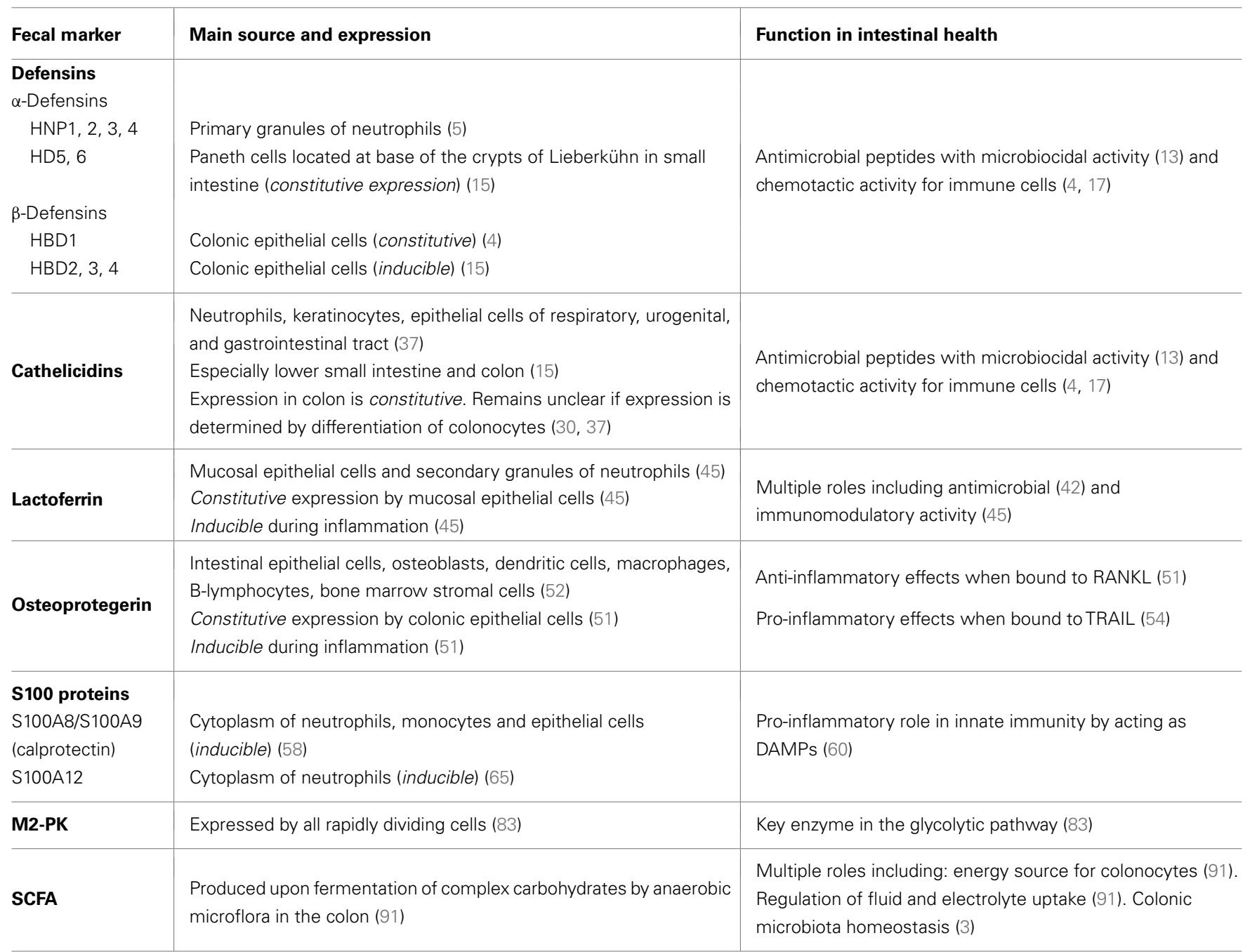

HNP, human neutrophil peptide; HD, human defensin; HBD, human $\beta$-defensin; RANKL, receptor activator of NF-kB ligand; TRAIL, tumor necrosis factor (TNF)-related apoptosis-inducing ligand; DAMPS, damage-associated molecular pattern molecules.

at this site (14). Like the $\alpha$-defensins, $\beta$-defensins also exhibit chemotactic activity for immature dendritic cells (DCs) and memory $\mathrm{T}$ cells through the CC chemokine receptor type 6 (CCR6), thus promoting adaptive immune responses by recruiting these cells to the site of microbial invasion (17).

\section{ROLE IN INTESTINAL DISEASE \\ Inflammatory bowel disease}

The expression of defensins in intestinal inflammation has been extensively studied, especially in the setting of inflammatory bowel disease (IBD) and its two main subsets, UC and Crohn's disease (CD). There is a consensus in the literature that in UC, which involves superficial inflammation confined to the colonic mucosa, increased HBD2 and Paneth cell $\alpha$-defensin expressions are characteristic (18). HBD2 levels were elevated in stool collected from children with active UC (median $356 \mathrm{ng} / \mathrm{g}$, range
40-527) compared to healthy controls (median $13 \mathrm{ng} / \mathrm{g}$, range $3-56 ; P=0.0002)(19)$.

In colonic $\mathrm{CD}$, there is attenuated induction of $\beta$-defensins as measured by mucosal mRNA (20). In ileal CD however, reduced Paneth cell $\alpha$-defensin expression was observed in ileal biopsies (21). Kapel and colleagues (19) found only a three- to fourfold increase in fecal HBD2 levels in children with CD as opposed to the abovementioned $>10$-fold increase in fecal HBD2 levels for UC. This impaired induction of $\beta$-defensins in colonic CD has been attributed to low $\beta$-defensin-gene copy number (22), while other studies have suggested an association between CARD15/NOD2 mutations and HBD2 deficiency (23). The $\alpha$-defensin deficiency in ileal CD has also been linked to NOD2 mutations (5). An important finding from the study by Kapel et al. (19) was a positive correlation between fecal calprotectin and HBD2, suggesting that fecal HBD2 is associated with intestinal inflammation. 


\section{Irritable bowel syndrome}

Irritable bowel syndrome (IBS) is a very common functional bowel disorder in the absence of macroscopic and histologic inflammation, characterized by abdominal pain and altered bowel habits (24). According to the ROME III criteria, IBS can be subtyped into diarrhea predominant (IBS-D), constipation predominant (IBSC), mixed diarrhea and constipation (IBS-M), and unsubtyped IBS (IBS-U) (25). There is mounting evidence that microbial dysbiosis is associated with IBS, with the implication of small intestinal bacterial overgrowth (SIBO) in its pathogenesis (26). This alteration in gut microbiota is hypothesized to lead to activation of the mucosal innate immune response (26), which has been supported by various studies. In particular, a study by Langhorst and co-workers comparing fecal HBD2 in patients with IBS, active UC, and healthy controls, found that fecal HBD2 was significantly elevated in the IBS group (mean \pm SD: $76.0 \pm 67.9 \mathrm{ng} / \mathrm{g}$ ) in comparison to controls $(29.9 \pm 16.1 \mathrm{ng} / \mathrm{g} ; P<0.001)$, although to a lesser extent than patients with active UC $(106.9 \pm 91.5 \mathrm{ng} / \mathrm{g})$. Their findings support the hypothesis of an activation of the mucosal innate defense in IBS toward low-grade mucosal inflammatory activity (24), which is in turn supported by studies that have found increased mast cells (27) and colonic lamina propria immune cells in patients with IBS (28).

\section{Necrotizing enterocolitis}

Necrotizing enterocolitis (NEC) is one of the most common gastrointestinal emergencies in neonates (29). Its main risk factors are prematurity and low birthweight (29). The pathogenesis of NEC remains elusive but there is strong evidence that inappropriate bacterial colonization of the neonatal gut plays a role (30). This has been supported by various studies showing that probiotic supplementation in preterm neonates of very low birthweight $(<1500 \mathrm{~g})$ reduces the risk and mortality of NEC (31). Like IBS, this aberrant postnatal bacterial colonization may lead to an activation of the innate immune system of the gut.

A study by Jenke and colleagues aimed to assess this intestinal mucosal innate response via HBD2 expression in extremely lowbirth-weight (ELBW) infants with NEC (32). They found that infants with moderate NEC had elevated fecal HBD2 concentrations before onset of symptoms, probably reflecting an adequate immune response (32). However, infants with severe NEC showed no increase in fecal HBD2 concentrations before and during the disease. This finding together with a lack of increase in fecal calprotectin concentration and normal villin expression, the latter of which is reduced with epithelial cell loss, suggests a specific deficiency of innate defense activation in ELBW infants rather than an impaired intestinal epithelial barrier, leading to a more severe course of NEC (32).

\section{CATHELICIDINS}

Cathelicidins are a family of precursor proteins with a wellconserved cathelin pro-region, followed by a highly variable Cterminal antimicrobial domain (33). Human cationic antimicrobial protein 18 (hCAP18) is the only human cathelicidin precursor protein, which is cleaved from the cathelin pro-region to produce the mature cathelicidin peptide LL-37 (33). The expression of cathelicidin is summarized in Table 2.

\section{ROLE IN HEALTH}

Proteolytic cleavage of hCAP18 into LL-37 is required for bactericidal activity. Like defensins and other AMPs, cathelicidin exhibits microbiocidal activity by disrupting microbial membrane integrity (13). In vitro studies have shown activity against a range of Gram-negative and Gram-positive bacteria including gastrointestinal pathogens such as Helicobacter, Salmonella, Shigella, and the fungus Candida albicans (15). Its antibacterial activity is mediated by the lipopolysaccharide (LPS)-binding and neutralizing properties of cathelicidin, thereby inhibiting LPS-induced cellular responses, such as the release of TNF- $\alpha$, nitric oxide, and tissue factor (34).

Cathelicidin contributes to host defenses by playing a role in the inflammatory process. It exhibits in vitro chemotactic activity for the selective migration of human peripheral blood monocytes, neutrophils, and $\mathrm{CD} 4^{+} \mathrm{T}$ cells (35). Cathelicidin is also chemotactic for mast cells, inducing their degranulation, resulting in the release of inflammatory mediators like neutrophil chemoattractants and histamine, which increases vascular permeability, thus further facilitating neutrophil infiltration of inflamed tissue (36).

In addition, cathelicidin has been reported to help in the repair of damaged tissue and wound closure by promoting wound neovascularization and re-epithelialization of healing skin (34); its role in intestinal mucosal healing is unknown.

\section{ROLE IN INTESTINAL DISEASE \\ Inflammatory bowel disease}

A study looking at cathelicidin expression in colonic mucosal biopsies of UC, CD, and healthy patients found a significantly higher expression in patients with UC when compared to those with CD (33). However, when inflamed and non-inflamed mucosa of patients with UC or CD was compared, no difference in expression was found. In addition, increased CD4 expression levels (a surrogate marker of infiltrating immune cells) in inflamed CD mucosa were not associated with increased cathelicidin expression (33). These findings suggest the dissociation between cathelicidin expression and inflammation. Other studies have supported this by showing that pro-inflammatory mediators do not upregulate cathelicidin expression, whether in vitro or in vivo $(37,38)$.

Regulation of cathelicidin expression is unclear. Cathelicidin expression was reported to be regulated by butyrate (a SCFA) through butyrate-induced differentiation of colonic epithelial cells $(15,37)$. However, Schauber and colleagues (33) showed that butyrate-enhanced colonocyte differentiation and butyrateinduced cathelicidin expression are regulated separately via distinct signaling pathways.

\section{Shigellosis}

Shigellosis is a major cause of morbidity and mortality in developing countries (39). It is caused by infection with the highly contagious Shigella species, which invades the colonic mucosa causing inflammation that destroys the mucosal barrier (40). The clinical manifestations are the passage of bloody mucoid loose stools, abdominal cramps, rectal tenesmus, and fever (40).

Reduced cathelicidin levels have been observed in gut biopsies of patients with shigellosis (41). It has been suggested that this 
down-regulation is a strategy by pathogenic microbes to increase their virulence by circumventing host immune defenses. Adjunct therapy with butyrate during shigellosis resulted in enhanced expression of cathelicidin in rectal epithelia, prolonged cathelicidin secretion in stool, and early reduction in inflammation (40).

\section{LACTOFERRIN}

Lactoferrin is an iron-binding glycoprotein of the transferrin family which plays a role in transporting serum iron (42). The expression pattern of lactoferrin (Table 2) indicates that it may play a role in the innate immune response (43).

\section{ROLE IN HEALTH}

Lactoferrin has multiple roles, some attributable to its ironbinding properties. Interestingly, lactoferrin is both promicrobial and antimicrobial, the former because of its ability to provide iron to bacteria. In contrast, its bacteriostatic activity is due to the sequestration of iron and subsequent deprivation of this nutrient from pathogenic bacteria (42). Furthermore, independent of its iron-binding properties, lactoferrin possesses bactericidal activity via direct interaction with bacteria (43). It was observed that apolactoferrin, the iron-free form of lactoferrin, can bind to the outer membrane of Gram-negative bacteria to cause the rapid release of LPS and an increase in membrane permeability (44). In addition, it is widely accepted that lactoferrin has antiviral, antifungal, and antiparasitic functions (42).

Lactoferrin is a modulator of the innate and adaptive immune system. Its anti-inflammatory activity is attributed to the inhibition of cytokines such as TNF- $\alpha$ and IL-1 $\beta$ (45). It has also been suggested that lactoferrin induces immunity via activation of various signaling pathways. Its positive charge allows it to bind to negatively charged molecules on the surface of various immune cells and this association may trigger signaling pathways that lead to cellular activation, proliferation, and differentiation. Lactoferrin is also transported into the nucleus where it can bind DNA and activate different signaling pathways (42).

\section{ROLE IN INTESTINAL DISEASE \\ Inflammatory bowel disease}

An increase in fecal lactoferrin levels occurs during intestinal inflammation (46) due to mucosal infiltration and degranulation of neutrophils, providing an additional source of lactoferrin to aid the mucosal innate response (45). Elevated fecal lactoferrin levels have been reported in IBD (47) with a sensitivity of 78\%, and specificity of $90 \%$ in identifying inflammation in adults with chronic UC and CD (46). In addition, fecal lactoferrin showed good correlation to disease activity (endoscopic and histopathologic) and was $100 \%$ specific in ruling out IBS (46). Using an established cutoff point of $7.25 \mu \mathrm{g} / \mathrm{mL}$ for patients with IBD (48), similar findings of elevated fecal lactoferrin in pediatric patients with UC $(1880 \pm 565 \mu \mathrm{g} / \mathrm{mL})$ and CD $(1701 \pm 382 \mu \mathrm{g} / \mathrm{mL})$ compared to healthy controls $(1.17 \pm 0.47 \mu \mathrm{g} / \mathrm{mL} ; P<0.001)$ were observed (49). Fecal lactoferrin also correlated well with clinical activity indices and erythrocyte sedimentation rate (ESR) (49).

\section{OSTEOPROTEGERIN}

Osteoprotegerin is a member of the tumor necrosis factor (TNF) receptor superfamily and functions as a soluble decoy receptor of the receptor activator of NF- $\kappa \mathrm{B}$ ligand (RANKL) and TNF-related apoptosis-inducing ligand (TRAIL) (Table 2) $(50,51)$.

\section{ROLE IN HEALTH}

\section{Receptor activator of $N \mathrm{~F}-\mathrm{\kappa} B$ ligand}

Osteoprotegerin is best known for its role in bone metabolism. It binds to RANKL and blocks its interaction with RANK, thereby inhibiting osteoclastogenesis (52). In addition, the RANK/RANKL/OPG system has a role in regulating intestinal inflammation by modulation of colonic DCs. In a murine model, exogenous OPG reduced DC survival, eliminating the antigenpresenting cell (APC) for colonic $\mathrm{CD}^{+}{ }^{+} \mathrm{T}$ cells, thereby reducing inflammation (53).

\section{TNF-related apoptosis-inducing ligand}

TNF-related apoptosis-inducing ligand is a member of the TNF ligand superfamily that induces cellular apoptosis. The interaction of OPG with TRAIL during intestinal inflammation inhibits apoptosis of DCs and activated T cells, thereby perpetuating intestinal immune activation (54). This pro-inflammatory effect opposes the above findings of a potent anti-inflammatory effect of OPG when interacting with RANKL (53).

\section{ROLE IN INTESTINAL DISEASE}

\section{Inflammatory bowel disease}

The role of OPG in intestinal inflammation was affirmed by a study of children with newly diagnosed CD that showed elevated serum and intestinal mucosal OPG levels (52). Importantly, fecal OPG was also raised in moderate/severe CD $(6463 \pm 8691 \mathrm{pg} / \mathrm{mL})$ and mild CD $(477 \pm 848 \mathrm{pg} / \mathrm{mL})$ when compared to healthy controls $(63 \pm 0.001 \mathrm{pg} / \mathrm{mL} ; P<0.0001)$. It was proposed that the excess circulating OPG was a result of increased mucosal OPG production due to inflammation. In addition, serum and fecal OPG decreased after treatment with exclusive enteral nutrition (EEN). This indicates that fecal OPG can be used as a marker of mucosal OPG expression and intestinal inflammatory severity in CD.

A recent study has provided further insight into the role of OPG in intestinal inflammation. Via in vitro methods, Nahidi and co-workers (55) found that OPG possesses pro-inflammatory properties via its induction of gut barrier dysfunction and secretion of pro-inflammatory cytokines. Their results also provide evidence that OPG, like TNF- $\alpha$, exerts its pro-inflammatory effects by NF- $\kappa$ B activation.

\section{Cryptosporidiosis}

Cryptosporidiosis is caused by infection with the waterborne protozoan parasite Cryptosporidium (56). It characteristically results in watery diarrhea (56) that is usually self-limited in immunocompetent individuals (57) but may be profuse and prolonged in immunocompromised patients (56).

The "disease-promoting" effect of OPG mediated by TRAIL, as discussed above, was further alluded to in an in vitro study of human ileal mucosal cells infected with Cryptosporidium (57). The results showed that treatment with TRAIL induced epithelial cell apoptosis and reduced parasite numbers. However, giving recombinant OPG blocked these therapeutic effects. Moreover, this study showed an early increase in OPG expression 
by the infected epithelial cells, suggesting that Cryptosporidium may upregulate OPG to protect against early apoptosis by TRAIL.

\section{S100 PROTEINS}

S100 proteins are a family of more than 20 calcium-binding proteins (58). Unlike many of the other S100 proteins that exert their regulatory effects in a $\mathrm{Ca}^{2+}$-dependent manner solely within the cells they are expressed, three S100 proteins-S100A8, S100A9, and S100A12, have also been found to have extracellular activity (59). These three members are, moreover, specifically associated with innate immune functions due to their expression in phagocytes (60). S100A8 and S100A9 associate to form a complex known as calprotectin (58). The expression of calprotectin and S100A12 is summarized in Table 2.

\section{ROLE IN HEALTH}

Calprotectin (S100A8/S100A9) and S100A12 have a proinflammatory role in innate immunity and are part of a group called damage-associated molecular pattern molecules (DAMPs), due to their release by activated or damaged cells under conditions of cellular stress (60). An emerging concept of pattern recognition involves sensing of exogenous pathogen-associated molecular patterns (PAMPs) and endogenous DAMPs via the multiligand receptor for advanced glycation end products (RAGE) and toll-like receptors (TLRs), enabling innate immunity to achieve our primary host defense against invading microorganisms and non-specific stress factors $(58,60)$.

In accordance with their pro-inflammatory role, calprotectin and S100A12 are significantly overexpressed at sites of inflammation, and there is a strong correlation of their serum concentrations to inflammation (60). The secretion of calprotectin by phagocytes is induced when phagocytes come into contact with inflamed endothelium. One mechanism that calprotectin is thought to promote inflammation is via induction of proinflammatory chemokines, adhesion molecules (e.g., VCAM1 and ICAM-1) and $\beta_{2}$-integrin, thereby mediating leukocyte recruitment, adhesion, and transendothelial migration to inflamed tissue $(58,61)$.

S100A12 has also been shown to mediate inflammation via the induction of similar adhesion molecules to calprotectin and it also upregulates the production of pro-inflammatory cytokines by macrophages, including TNF- $\alpha$ and IL-1 $\beta$ (58). Moreover, it has been implicated in a novel pro-inflammatory axis binding RAGE, leading to the transduction of pro-inflammatory signals in the endothelium and immune cells (60).

The pediatric reference range for fecal calprotectin was established in a study of 117 healthy children and found a median of $13.6 \mu \mathrm{g} / \mathrm{g}$ (95\% confidence interval, 9.9-19.5 $\mu \mathrm{g} / \mathrm{g}$ ) (62). It was also suggested that the adult cutoff level for intestinal inflammation of $50 \mu \mathrm{g} / \mathrm{g}$ can be applied to children as well (62). More recently, a pediatric reference range for S100A12 has also been determined in a study involving 56 healthy children (63). A median of $0.5 \mathrm{mg} / \mathrm{kg}$ (range $0.39-25 \mathrm{mg} / \mathrm{kg}$ ) was found, suggesting that the established adult cutoff of $10 \mathrm{mg} / \mathrm{kg}$ can also be applied to children (63).

\section{ROLE IN INTESTINAL DISEASE Inflammatory bowel disease}

S100 proteins, especially calprotectin and S100A12, have been extensively studied in both the adult and pediatric IBD populations. Serum and mucosal levels of both of these biomarkers have been shown to be elevated in children with IBD (64).

Fecal calprotectin levels are also significantly elevated in children with IBD (median $1265 \mathrm{mg} / \mathrm{kg}$ ) compared to children without IBD (median $30.5 \mathrm{mg} / \mathrm{kg} ; P<0.0001$ ). A sensitivity of $100 \%$ and specificity of $67 \%$ was found for fecal calprotectin in identifying children with IBD (cutoff $>50 \mathrm{mg} / \mathrm{kg}$ for IBD) (65). In addition, multiple studies have shown that fecal calprotectin correlates closely with endoscopic and histological grading of colonic inflammation in both UC and CD (66-68). A positive correlation between fecal calprotectin and clinical activity indices in both $\mathrm{CD}$ and UC has also been demonstrated (69) and therefore, fecal calprotectin has been proposed as a useful tool in monitoring disease activity in children with IBD (67).

Together, there is substantial evidence in the literature that fecal calprotectin is a sensitive marker of intestinal inflammation. Multiple studies have shown that fecal calprotectin can differentiate IBD from functional disorders like IBS $(69,70)$, with validation in children $(67,71)$. Based on a cutoff of $30 \mathrm{mg} / \mathrm{kg}$, fecal calprotectin discriminated adults with active CD from those with IBS with $100 \%$ sensitivity and $97 \%$ specificity (72). However, it is not a disease-specific fecal marker and is also elevated in other gastrointestinal disorders like gastroenteritis (73) and colorectal cancer (CRC) (70), as well as during non-steroidal and non-inflammatory drug use (74).

Another potential aspect of fecal calprotectin is in predicting relapse in children with IBD. An elevated calprotectin level in stool was found to be associated with a 13-fold increased risk of relapse in adult IBD patients experiencing remission (75), with another study suggesting that fecal calprotectin is more accurate in predicting relapse in UC than CD (76).

S100A12 is also elevated in stool from children with active IBD (median $95.40 \mathrm{mg} / \mathrm{kg}$; range $6.19-349.9 \mathrm{mg} / \mathrm{kg}$ ) compared to healthy controls (median $0.69 \mathrm{mg} / \mathrm{kg}$; range $0.39-17.73 \mathrm{mg} / \mathrm{kg}$; $P<0.0001$ ) (77). Moreover, it was found to have a sensitivity of $96 \%$ and specificity of $92 \%$ in distinguishing children with active IBD from healthy controls when a $10 \mathrm{mg} / \mathrm{kg}$ fecal S100A12 was used as a cutoff.

\section{Cystic fibrosis}

Cystic fibrosis (CF) is the most common life-shortening autosomal recessive disease in Caucasians, with an incidence of 1 in 2500 live births (78). There is evidence that CF predisposes to inflammatory changes not only in the respiratory system but also in the gastrointestinal tract (79).

In comparison to the abovementioned biomarkers, calprotectin has been more widely studied in CF. A study looking at children with CF found elevated fecal calprotectin levels and rectal nitric oxide production in majority of the subjects, indicating that intestinal inflammation is a major feature in CF (79). These values fell significantly after administration of the probiotic Lactobacillus GG, suggesting that the intestinal microbiota plays a role in $\mathrm{CF}$ intestinal inflammation (79). This was supported by Werlin and 
co-workers (78), who used wireless capsule endoscopy (WCE) and fecal calprotectin to investigate intestinal inflammation in children with CF. Fecal calprotectin was elevated only in pancreatic insufficient (PI) subjects, whereas WCE showed a high prevalence of small bowel injury in both PI and pancreatic sufficient (PS) children. The authors suggested that these findings support a " $\mathrm{CF}$ enteropathy" that is a primary feature of the CF phenotype and that its inflammatory component (as reflected by fecal calprotectin) changes with the degree of exocrine pancreatic impairment (78).

Nevertheless, it has been suggested that fecal sampling assessing intestinal inflammation in CF may potentially give false positive results due to the cross-reaction of ingested sputum proteins with intestinal inflammatory markers. However, this is likely a minor confounder to the significantly elevated fecal calprotectin detected in patients with CF (80).

In contrast, results from a recent study showed that unlike calprotectin, fecal S100A12 levels were not elevated in children with CF when compared to healthy controls (81).

\section{M2-PYRUVATE KINASE \\ ROLE IN HEALTH}

Pyruvate kinase (PK) is a key enzyme in the glycolytic pathway that catalyzes the conversion of phosphoenolpyruvate into pyruvate with eventual ATP production (82). It is expressed in all cells (83) and exists as dimeric and tetrameric isotypes in humans (84). The tetrameric (M1) type is found in skeletal muscles, heart, and brain (84), while the dimeric (M2) form is expressed by all rapidly dividing cells (both neoplastic and non-neoplastic) (83) (Table 2).

\section{ROLE IN INTESTINAL DISEASE}

Increased concentrations of fecal M2-PK are found in patients with CRC and M2-PK has been proposed as a potential screening tool for this cancer, with a sensitivity of $73 \%$ and specificity of $78 \%$ (85). Other studies have reported enhanced M2-PK activity in neutrophils in patients with polytrauma (86) and chronic cardiac failure (87). The role of M2-PK in gastrointestinal inflammation is unraveling (84), with several studies reporting its potential as a novel marker of intestinal inflammation.

\section{Inflammatory bowel disease}

In active IBD, there is increased intestinal epithelial cell turnover and rapid division (84). Hence, given the relationship of M2-PK to cell division, it has been postulated that fecal M2-PK concentrations are elevated in IBD patients (83). This has been supported by several studies.

Chung-Faye and co-workers (83) found fecal M2-PK to be significantly elevated in 81 adults with IBD and 7 with CRC when compared to 43 with IBS. Using a cutoff of $3.7 \mathrm{U} / \mathrm{mL}$, fecal M2-PK had a sensitivity of $73 \%$ and specificity of $74 \%$ when used as a marker of organic gastrointestinal disease. Furthermore, M2-PK levels were greater in IBD patients with active compared to inactive disease. Their results also showed a high correlation between fecal M2-PK and calprotectin.

A pediatric study reported similar findings of significantly higher PK immunoreactivity in IBD patients $(143.7 \pm 24.6 \mathrm{U} / \mathrm{g})$ when compared to healthy controls $(1.2 \pm 0.4 \mathrm{U} / \mathrm{g} ; P<0.00001)$ (82). Using the manufacturer recommended cutoff of $4 \mathrm{U} / \mathrm{g}$, sensitivities of 94.3 and $100 \%$ were found for $\mathrm{UC}$ and CD, respectively.
When a second cutoff of $5 \mathrm{U} / \mathrm{g}$ was used, false positives were reduced. However, specificity fell from $97.1 \%$ (cutoff of $4 \mathrm{U} / \mathrm{g}$ ) to $94.3 \%$ (cutoff of $5 \mathrm{U} / \mathrm{g}$ ) and sensitivity for CD fell to $94.1 \%$. Regardless, the high sensitivity and specificity reflect the potential use of the fecal M2-PK test in pediatric IBD.

A more recent multicentre cohort study compared the ability of four fecal markers (calprotectin, lactoferrin, M2-PK, and S100A12) to predict the outcome in severe acute pediatric UC (88). Although all four markers reflected disease severity by their very elevated fecal values, only M2-PK had sufficient ability to predict corticosteroid treatment failure and the need for secondline therapy, presenting the potential for fecal M2-PK testing to be incorporated into clinical practice with further research. However, it was still inferior to the Pediatric UC activity index (PUCAI).

\section{Pouchitis}

Two studies looking at ileal pouch-anal anastomosis (IPAA) in patients with UC and familial adenomatous polyposis (FAP) who underwent restorative proctocolectomy found that those with pouchitis had significantly higher fecal M2-PK levels $(89,90)$. Johnson and colleagues (90) found that fecal M2-PK could differentiate between non-inflamed and inflamed pouches with a sensitivity and specificity of 80 and $70.6 \%$, respectively. Moreover, fecal M2-PK levels correlated significantly with disease activity indices, endoscopic and histological appearances, as well as the degree of neutrophilic infiltration (90). These findings were mirrored in the earlier study despite a smaller sample size (89).

\section{SHORT-CHAIN FATTY ACIDS}

Short-chain fatty acids are produced when colonic microflora ferment complex carbohydrates that are not absorbed in the small intestine (91) (Table 2). The main SCFAs liberated in the colon are propionate, acetate, and butyrate and their production can be altered by diet and rate of transit (3). The type of substrates derived from a person's diet influences the production of SCFA. For instance, pectin is a particularly good source of acetate, while starch, oat, and wheat bran give rise to high amounts of butyrate (91). Antibiotics, especially those effective against Gramnegative and anaerobic bacteria, can also alter colonic SCFA production by reducing the fermentative capacity of the intestinal microflora (91).

\section{ROLE IN HEALTH}

Short-chain fatty acids have a wide range of actions. They are absorbed and metabolized rapidly by colonocytes, providing 60 $70 \%$ of their energy requirements (91). They also regulate fluid and electrolyte uptake via activation of apical $\mathrm{Na}^{+} / \mathrm{H}^{+}$exchange (91). Their presence in the colon lowers the $\mathrm{pH}$, thus preventing the overgrowth of $\mathrm{pH}$-sensitive pathogenic bacteria. Human rectal SCFA infusions have also shown to increase splanchnic blood flow and decrease gastric tone (3).

Butyrate, in particular, plays an important role in intestinal health. It has been shown to have a trophic effect on colorectal and ileal mucosal cells but despite this, is able to maintain normal colonic phenotype via growth arrest, differentiation, and apoptosis, thereby lowering the risk of malignancy. Importantly, butyrate enhances the gastrointestinal innate immunity by acting as a relay 
for transducing information from the luminal environment to the mucosal immune system via up-regulation of TLR expression (92). These TLRs enable the epithelium to differentiate commensal flora from pathogens, via recognition of bacterial molecular patterns called PAMPs and induce the transcription of a panel of genes mediating immune and inflammatory responses (92).

\section{ROLE IN INTESTINAL DISEASE \\ Inflammatory bowel disease}

Butyrate has anti-inflammatory effects that are mediated by the inhibition of NF- $\kappa \mathrm{B}$ (i.e., inhibiting NF- $\mathrm{B}$ nuclear translocation) in human colonic epithelial cells, therefore suppressing the gene transcription of pro-inflammatory cytokines. Histone deacetylase inhibition is the proposed mechanism behind this reduction in NF- $\mathrm{B}$ translocation (93). The anti-inflammatory effects of butyrate have been demonstrated in UC, where butyrate enemas resulted in improved clinical disease activity and histological inflammation (94). The same anti-inflammatory effect was seen in $\mathrm{CD}$, where butyrate reduced the expression of pro-inflammatory cytokines by intestinal biopsy specimens from CD patients (95).

\section{Diversion colitis}

Following the formation of an ileostomy, or after proximal colectomy for conditions such as IBD, where there is surgical diversion of the fecal stream (91), diversion colitis can develop due to the reduction in luminal butyrate levels (96). This results from the loss of butyrate as an energy source for colonocytes as well as a lack of its trophic effects on the colon (91). The anti-inflammatory effects of SCFAs were reiterated in a study which showed that SCFA-irrigation reversed the mucosal abnormalities in patients with diversion colitis (97).

\section{Diarrheal disorders}

Short-chain fatty acids have been found to have a role in diarrheal disorders, in accordance with their ability to stimulate fluid and electrolyte uptake. A study on cholera in children found that including rice starch in oral rehydration salts (ORS) resulted in faster clinical recovery (98). This was associated with striking increases in fecal bacterial concentrations and SCFA levels with time, indicating that this therapeutic effect might be mediated by SCFA enhancing sodium and water absorption and providing colonocytes with energy (98).

Short-chain fatty acids have also been implicated in the development of antibiotic-associated diarrhea (AAD). A study aimed at elucidating the pathogenesis of AAD found very low SCFA production in AAD patients versus controls (99). It is unclear whether $\mathrm{AAD}$ is secondary to impaired colonic fermentation resulting in decreased SCFA-stimulated sodium and water absorption, or the reduction in SCFA production is due to decreased colonic bacterial count (99).

\section{Cystic fibrosis}

It has been hypothesized that malabsorption of carbohydrates and to a lesser extent, protein, that occurs in CF associated with pancreatic insufficiency, can serve as substrates for fermentation by colonic microflora, thus leading to an increase in SCFA production and excretion in stool (100). Increased fecal SCFA output
( $50 \pm 30 \mathrm{mmol} /$ day) was found in patients with pancreatic insufficiency secondary to chronic pancreatitis unrelated to CF when compared to healthy individuals $(10-20 \mathrm{mmol} /$ day) (101). This finding of increased SCFA production in a maldigestive state similar to CF might indicate mechanisms other than pancreatic insufficiency in determining fecal SCFA output in CF patients. Notably, SCFA derivatives have been shown to correct the $\triangle$ F508-CFTR mutation in vitro, by correcting the inability of the $\Delta$ F508-CFTR protein to traffic to the cell surface membrane and by activating alternate chloride transport pathways (102).

\section{PRACTICAL ASPECTS OF FECAL BIOMARKERS}

Of the markers discussed, all except SCFA can be measured in stool via sandwich ELISAs, which are mostly commercially available and therefore easily performed in a routine laboratory.

There is limited information on the stability of defensins in stool. In preparation for one study (19), the authors looked at three sample storage conditions $-48 \mathrm{~h}$ at room temperature, 1 week at $4^{\circ} \mathrm{C}$, and 3 months at $-80^{\circ} \mathrm{C}-$ and observed no significant difference in HBD2 levels in stool. These results suggest that fecal samples can be stored in a patient's home refrigerator for up to a week prior to laboratory testing, therefore enhancing the clinical utility of the test. On the contrary, no information regarding the stability of cathelicidin in stool has been found.

Lactoferrin, calprotectin, and S100A12 are stable in stool at room temperature for up to 4,7 , and more than 7 days, respectively (58). In addition to the resistance of lactoferrin to proteolysis in stool, it is unaffected by multiple freeze-thaw cycles (84). Calprotectin and S100A12 also have a homogenous distribution in stool (58). These features increase the convenience and acceptability of sample collection to children and parents, with the potential to use regular mail for the $S 100$ proteins. They also ensure the accuracy of measurement via ELISA in the laboratory, further enhancing their desirability as fecal biomarkers.

M2-pyruvate kinase is stable for 2 days at room temperature in stool (84). Commercial ELISAs have been previously developed and validated for use in CRC screening and are thus readily available.

Osteoprotegerin, on the other hand, decays rapidly in stool within $24 \mathrm{~h}$ at room temperature (54). This means that samples have to be freshly collected and kept frozen at $-80^{\circ} \mathrm{C}$ until tested.

Measurement of SCFA in stool is done via high-performance liquid chromatography (HPLC), therefore requiring additional expertise and laboratory equipment than an ELISA. SCFA, both volatile and non-volatile, are found to be stable in stool for at least 7 days at room temperature if samples are treated with $70 \%$ ethanol (103). Fecal samples are suggested to be treated immediately after defecation (103), which may be inconvenient for patients. A further drawback of measuring fecal levels of SCFA is that $<5 \%$ of SCFA produced in the colon is excreted in stool (91). Moreover, fecal SCFA can be altered by diet and rate of transit, and therefore may only be useful in reflecting changes in excretion but not in production. Alternative methods for measuring SCFA are the breath gas test and peripheral venous SCFA. However, these methods are general indicators of SCFA fermentation and not intestinal specific (3). These disadvantages presented in the literature affect 
the feasibility and clinical utility of measuring SCFA in stool to a fair extent.

\section{AREAS FOR CONSIDERATION AND FUTURE RESEARCH}

Currently, the clinical role of fecal biomarkers is better established in diseases like IBD, with a paucity of information in other states of gastrointestinal disease and inflammation. More research into these biomarkers has to be performed before they can be used to accurately define the basic biological processes and pathogenesis of disease. With more research to further our understanding of these biomarkers, there is the potential for them to be incorporated into clinical practice. Although endoscopy with tissue biopsies is at present the only accurate means of detecting intestinal inflammation (58), testing of fecal biomarkers can be used as an initial screening test to determine the need for more invasive investigations. Their non-invasive nature is also especially valuable in the pediatric population. Furthermore, the analysis of these biomarkers directly from stool provide intestinal-specific information as opposed to the commonly used serum markers such as C-reactive protein (CRP) and ESR, which reflect a summation of systemic inflammatory responses (58). Therefore, fecal biomarkers may be a viable option for monitoring disease activity in the follow-up of patients and assessing their response to antiinflammatory therapies. The current lack of age-related reference ranges of these biomarkers in healthy children, apart from calprotectin and S100A12, needs to be addressed. In addition, with future work to more clearly define healthy from disease levels, these biomarkers can be used for risk stratification in patients to direct therapy and predict clinical outcomes.

In addition to protein biomarkers, intestinal microbes and microbial products also have the potential to be used as disease markers. However at present, more research into their role in healthy and disease states has to be done. Therefore, they are less applicable to clinical practice in the immediate future as compared to protein biomarkers. With reducing costs and the automation of high-throughput sequencing, microbes and their products show great promise as disease markers for future clinical use (104). A further advantage is that determining specific compositions of gut microbiota in disease states may provide more insight into the causes of such diseases. This is in contrast to quantifying protein biomarkers, which reflect more on the effects of disease states.

\section{CONCLUSION}

There are various biomarkers, a few of which have been reviewed above, that may be useful in providing insight into the role of intestinal health and disease, and the development of nongastrointestinal conditions associated with intestinal dysbiosis. There is a current lack of literature on the normal ranges as well as age-related changes of these biomarkers in healthy children, which limit the applicability of these fecal biomarkers in a general clinical setting.

\section{ACKNOWLEDGMENTS}

The authors thank The Australian Cystic Fibrosis Research Trust (Chee Y. Ooi), The Royal Australasian College of Physicians Foundation (Servier Staff Research Fellowship) (Chee Y. Ooi), and The Sydney Children's Hospital Foundation (Tamarah Katz) for their support and generosity.

\section{REFERENCES}

1. Muller CA, Autenrieth IB, Peschel A. Innate defenses of the intestinal epithelial barrier. Cell Mol Life Sci (2005) 62(12):1297-307. doi:10.1007/s00018-0055034-2

2. Dommett R, Zilbauer M, George JT, Bajaj-Elliott M. Innate immune defence in the human gastrointestinal tract. Mol Immunol (2005) 42(8):903-12. doi:10.1016/j.molimm.2004.12.004

3. Topping DL, Clifton PM. Short-chain fatty acids and human colonic function: roles of resistant starch and nonstarch polysaccharides. Physiol Rev (2001) 81(3):1031-64.

4. Yuan Q, Walker WA. Innate immunity of the gut: mucosal defense in health and disease. J Pediatr Gastroenterol Nutr (2004) 38(5):463-73. doi:10.1097/ 00005176-200405000-00001

5. Ramasundara M, Leach ST, Lemberg DA, Day AS. Defensins and inflammation: the role of defensins in inflammatory bowel disease. J Gastroenterol Hepatol (2009) 24(2):202-8. doi:10.1111/j.1440-1746.2008.05772.x

6. Penders J, Thijs C, van den Brandt PA, Kummeling I, Snijders B, Stelma F, et al. Gut microbiota composition and development of atopic manifestations in infancy: the KOALA Birth Cohort Study. Gut (2007) 56(5):661-7. doi:10.1136/gut.2006.100164

7. Greiner T, Backhed F. Effects of the gut microbiota on obesity and glucose homeostasis. Trends Endocrinol Metab (2011) 22(4):117-23. doi:10.1016/j.tem. 2011.01.002

8. Giongo A, Gano KA, Crabb DB, Mukherjee N, Novelo LL, Casella G, et al. Toward defining the autoimmune microbiome for type 1 diabetes. ISME J (2011) 5(1):82-91. doi:10.1038/ismej.2010.92

9. Larsen N, Vogensen FK, van den Berg FW, Nielsen DS, Andreasen AS, Pedersen BK, et al. Gut microbiota in human adults with type 2 diabetes differs from non-diabetic adults. PLoS One (2010) 5(2):e9085. doi:10.1371/journal.pone. 0009085

10. Tang WH, Wang Z, Levison BS, Koeth RA, Britt EB, Fu X, et al. Intestinal microbial metabolism of phosphatidylcholine and cardiovascular risk. $N$ Engl J Med (2013) 368(17):1575-84. doi:10.1056/NEJMoa1109400

11. Willing BP, Dicksved J, Halfvarson J, Andersson AF, Lucio M, Zheng Z, et al. A pyrosequencing study in twins shows that gastrointestinal microbial profiles vary with inflammatory bowel disease phenotypes. Gastroenterology (2010) 139(6): 1844-54.e1. doi:10.1053/j.gastro.2010.08.049

12. Lee JM, Leach ST, Katz T, Day AS, Jaffe A, Ooi CY. Update of faecal markers of inflammation in children with cystic fibrosis. Mediators Inflamm (2012) 2012:948367. doi:10.1155/2012/948367

13. Zasloff M. Antimicrobial peptides of multicellular organisms. Nature (2002) 415(6870):389-95. doi:10.1038/415389a

14. Wehkamp J, Stange EF, Fellermann K. Defensin-immunology in inflammatory bowel disease. Gastroenterol Clin Biol (2009) 33(Suppl 3):S137-44. doi:10.1016/S0399-8320(09)73149-5

15. Wehkamp J, Schauber J, Stange EF. Defensins and cathelicidins in gastrointestinal infections. Curr Opin Gastroenterol (2007) 23(1):32-8. doi:10.1097/MOG. 0b013e32801182c2

16. Chaly YV, Paleolog EM, Kolesnikova TS, Tikhonov II, Petratchenko EV, Voitenok NN. Neutrophil alpha-defensin human neutrophil peptide modulates cytokine production in human monocytes and adhesion molecule expression in endothelial cells. Eur Cytokine Netw (2000) 11(2):257-66.

17. Yang D, Chertov O, Bykovskaia SN, Chen Q, Buffo MJ, Shogan J, et al. Betadefensins: linking innate and adaptive immunity through dendritic and T cell CCR6. Science (1999) 286(5439):525-8. doi:10.1126/science.286.5439.525

18. Fahlgren A, Hammarstrom S, Danielsson A, Hammarstrom ML. Increased expression of antimicrobial peptides and lysozyme in colonic epithelial cells of patients with ulcerative colitis. Clin Exp Immunol (2003) 131(1):90-101. doi:10.1046/j.1365-2249.2003.02035.x

19. Kapel N, Benahmed N, Morali A, Svahn J, Canioni D, Goulet O, et al. Fecal beta-defensin-2 in children with inflammatory bowel diseases. J Pediatr Gastroenterol Nutr (2009) 48(1):117-20. doi:10.1097/MPG.0b013e318174e872

20. Wehkamp J, Harder J, Weichenthal M, Mueller O, Herrlinger KR, Fellermann $\mathrm{K}$, et al. Inducible and constitutive beta-defensins are differentially expressed in Crohn's disease and ulcerative colitis. Inflamm Bowel Dis (2003) 9(4):215-23. doi:10.1097/00054725-200307000-00001

21. Wehkamp J, Salzman NH, Porter E, Nuding S, Weichenthal M, Petras RE, et al. Reduced Paneth cell alpha-defensins in ileal Crohn's disease. Proc Natl Acad Sci U S A (2005) 102(50):18129-34. doi:10.1073/pnas.0505256102 
22. Fellermann K, Stange DE, Schaeffeler E, Schmalzl H, Wehkamp J, Bevins CL, et al. A chromosome 8 gene-cluster polymorphism with low human betadefensin 2 gene copy number predisposes to Crohn disease of the colon. Am J Hum Genet (2006) 79(3):439-48. doi:10.1086/505915

23. Voss E, Wehkamp J, Wehkamp K, Stange EF, Schroder JM, Harder J. NOD2/CARD15 mediates induction of the antimicrobial peptide human betadefensin-2. J Biol Chem (2006) 281(4):2005-11. doi:10.1074/jbc.M511044200

24. Langhorst J, Junge A, Rueffer A, Wehkamp J, Foell D, Michalsen A, et al. Elevated human beta-defensin-2 levels indicate an activation of the innate immune system in patients with irritable bowel syndrome. Am J Gastroenterol (2009) 104(2):404-10. doi:10.1038/ajg.2008.86

25. Yao X, Yang YS, Cui LH, Zhao KB, Zhang ZH, Peng LH, et al. Subtypes of irritable bowel syndrome on Rome III criteria: a multicenter study. J Gastroenterol Hepatol (2012) 27(4):760-5. doi:10.1111/j.1440-1746.2011.06930.x

26. Simren M, Barbara G, Flint HJ, Spiegel BM, Spiller RC, Vanner S, et al. Intestinal microbiota in functional bowel disorders: a Rome foundation report. Gut (2013) 62(1):159-76. doi:10.1136/gutjnl-2012-302167

27. O'Sullivan M, Clayton N, Breslin NP, Harman I, Bountra C, McLaren A, et al. Increased mast cells in the irritable bowel syndrome. Neurogastroenterol Motil (2000) 12(5):449-57. doi:10.1046/j.1365-2982.2000.00221.x

28. Salzmann JL, Peltier-Koch F, Bloch F, Petite JP, Camilleri JP. Morphometric study of colonic biopsies: a new method of estimating inflammatory diseases. Lab Invest (1989) 60(6):847-51.

29. Lin PW, Stoll BJ. Necrotising enterocolitis. Lancet (2006) 368(9543):1271-83. doi:10.1016/S0140-6736(06)69525-1

30. Lin PW, Nasr TR, Stoll BJ. Necrotizing enterocolitis: recent scientific advances in pathophysiology and prevention. Semin Perinatol (2008) 32(2):70-82. doi:10.1053/j.semperi.2008.01.004

31. Deshpande G, Rao S, Patole S. Probiotics for prevention of necrotising enterocolitis in preterm neonates with very low birthweight: a systematic review of randomised controlled trials. Lancet (2007) 369(9573):1614-20. doi:10.1016/S0140-6736(07)60748-X

32. Jenke AC, Zilbauer M, Postberg J, Wirth S. Human beta-defensin 2 expression in ELBW infants with severe necrotizing enterocolitis. Pediatr Res (2012) 72(5):513-20. doi:10.1038/pr.2012.110

33. Schauber J, Rieger D, Weiler F, Wehkamp J, Eck M, Fellermann K, et al. Heterogeneous expression of human cathelicidin hCAP18/LL-37 in inflammatory bowel diseases. Eur J Gastroenterol Hepatol (2006) 8(6):615-21. doi:10.1097/00042737-200606000-00007

34. Zanetti M. Cathelicidins, multifunctional peptides of the innate immunity. J Leukoc Biol (2004) 75(1):39-48. doi:10.1189/jlb.0403147

35. De Y, Chen Q, Schmidt AP, Anderson GM, Wang JM, Wooters J, et al. LL-37, the neutrophil granule- and epithelial cell-derived cathelicidin, utilizes formyl peptide receptor-like 1 (FPRL1) as a receptor to chemoattract human peripheral blood neutrophils, monocytes, and T cells. J Exp Med (2000) 192(7):1069-74. doi:10.1084/jem.192.7.1069

36. Niyonsaba F, Iwabuchi K, Someya A, Hirata M, Matsuda H, Ogawa H, et al. A cathelicidin family of human antibacterial peptide LL-37 induces mast cell chemotaxis. Immunology (2002) 106(1):20-6. doi:10.1046/j.1365-2567.2002. 01398.x

37. Hase K, Eckmann L, Leopard JD, Varki N, Kagnoff MF. Cell differentiation is a key determinant of cathelicidin LL-37/human cationic antimicrobial protein 18 expression by human colon epithelium. Infect Immun (2002) 70(2):953-63. doi:10.1128/IAI.70.2.953-963.2002

38. Schauber J, Svanholm C, Termen S, Iffland K, Menzel T, Scheppach W, et al. Expression of the cathelicidin LL-37 is modulated by short chain fatty acids in colonocytes: relevance of signalling pathways. Gut (2003) 52(5):735-41. doi:10.1136/gut.52.5.735

39. Raqib R, Sarker P, Bergman P, Ara G, Lindh M, Sack DA, et al. Improved outcome in shigellosis associated with butyrate induction of an endogenous peptide antibiotic. Proc Natl Acad Sci U S A (2006) 103(24):9178-83. doi:10.1073/pnas.0602888103

40. Raqib R, Sarker P, Mily A, Alam NH, Arifuzzaman AS, Rekha RS, et al. Efficacy of sodium butyrate adjunct therapy in shigellosis: a randomized, double-blind, placebo-controlled clinical trial. BMC Infect Dis (2012) 12:111. doi:10.1186/1471-2334-12-111

41. Islam D, Bandholtz L, Nilsson J, Wigzell H, Christensson B, Agerberth B, et al. Downregulation of bactericidal peptides in enteric infections: a novel immune escape mechanism with bacterial DNA as a potential regulator. Nat Med (2001) 7(2):180-5. doi:10.1038/84627

42. Gonzalez-Chavez SA, Arevalo-Gallegos S, Rascon-Cruz Q. Lactoferrin: structure, function and applications. Int J Antimicrob Agents (2009) 33(4): 301.e1-8. doi:10.1016/j.ijantimicag.2008.07.020

43. Farnaud S, Evans RW. Lactoferrin - a multifunctional protein with antimicrobial properties. Mol Immunol (2003) 40(7):395-405. doi:10.1016/S01615890(03)00152-4

44. Ellison RT III, Giehl TJ. Killing of Gram-negative bacteria by lactoferrin and lysozyme. J Clin Invest (1991) 88(4):1080-91. doi:10.1172/JCI115407

45. Ward PP, Uribe-Luna S, Conneely OM. Lactoferrin and host defense. Biochem Cell Biol (2002) 80(1):95-102. doi:10.1139/o01-214

46. Kane S. Fecal lactoferrin is a sensitive and specific marker in identifying intestinal inflammation. Am J Gastroenterol (2003) 98(6):1309-14. doi:10.1111/j. 1572-0241.2003.07458.x

47. Abraham BP, Kane S. Fecal markers: calprotectin and lactoferrin. Gastroenterol Clin North Am (2012) 41(2):483-95. doi:10.1016/j.gtc.2012.01.007

48. Parsi MA, Shen B, Achkar JP, Remzi FF, Goldblum JR, Boone J, et al. Fecal lactoferrin for diagnosis of symptomatic patients with ileal pouch-anal anastomosis. Gastroenterology (2004) 126(5):1280-6. doi:10.1053/j.gastro.2004.02.012

49. Walker TR, Land ML, Kartashov A, Saslowsky TM, Lyerly DM, Boone JH, et al. Fecal lactoferrin is a sensitive and specific marker of disease activity in children and young adults with inflammatory bowel disease. J Pediatr Gastroenterol Nutr (2007) 44(4):414-22. doi:10.1097/MPG.0b013e3180308d8e

50. Chakravarti A, Marceau AA, Flamand L, Poubelle PE. Normal human primary CD4+ T lymphocytes synthesize and release functional osteoprotegerin in vitro. Lab Invest (2008) 88(2):171-84. doi:10.1038/labinvest.3700701

51. Vidal K, Serrant P, Schlosser B, van den Broek P, Lorget F, Donnet-Hughes A. Osteoprotegerin production by human intestinal epithelial cells: a potential regulator of mucosal immune responses. Am J Physiol Gastrointest Liver Physiol (2004) 287(4):G836-44. doi:10.1152/ajpgi.00428.2003

52. Nahidi L, Leach ST, Sidler MA, Levin A, Lemberg DA, Day AS. Osteoprotegerin in pediatric Crohn's disease and the effects of exclusive enteral nutrition. Inflamm Bowel Dis (2011) 17(2):516-23. doi:10.1002/ibd.21361

53. Ashcroft AJ, Cruickshank SM, Croucher PI, Perry MJ, Rollinson S, Lippitt JM, et al. Colonic dendritic cells, intestinal inflammation, and $\mathrm{T}$ cell-mediated bone destruction are modulated by recombinant osteoprotegerin. Immunity (2003) 19:849-61. doi:10.1016/S1074-7613(03)00326-1

54. Sylvester FA, Turner D, Draghi A II, Uuosoe K, McLernon R, Koproske K, et al. Fecal osteoprotegerin may guide the introduction of second-line therapy in hospitalized children with ulcerative colitis. Inflamm Bowel Dis (2011) 17(8):1726-30. doi:10.1002/ibd.21561

55. Nahidi L, Leach ST, Lemberg DA, Day AS. Osteoprotegerin exerts its proinflammatory effects through nuclear factor- $\kappa \mathrm{B}$ activation. Dig Dis Sci (2013) 58(11):3144-55. doi:10.1007/s10620-013-2851-2

56. Bouzid M, Hunter PR, Chalmers RM, Tyler KM. Cryptosporidium pathogenicity and virulence. Clin Microbiol Rev (2013) 26(1):115-34. doi:10.1128/CMR. 00076-12

57. Castellanos-Gonzalez A, Yancey LS, Wang HC, Pantenburg B, Liscum KR, Lewis DE, et al. Cryptosporidium infection of human intestinal epithelial cells increases expression of osteoprotegerin: a novel mechanism for evasion of host defenses. J Infect Dis (2008) 197(6):916-23. doi:10.1086/528374

58. Foell D, Wittkowski H, Roth J. Monitoring disease activity by stool analyses: from occult blood to molecular markers of intestinal inflammation and damage. Gut (2009) 58(6):859-68. doi:10.1136/gut.2008.170019

59. Donato R. Intracellular and extracellular roles of S100 proteins. Microsc Res Tech (2003) 60(6):540-51. doi:10.1002/jemt.10296

60. Foell D, Wittkowski H, Vogl T, Roth J. S100 proteins expressed in phagocytes: a novel group of damage-associated molecular pattern molecules. J Leukoc Biol (2007) 81(1):28-37. doi:10.1189/jlb.0306170

61. Newton RA, Hogg N. The human S100 protein MRP-14 is a novel activator of the beta 2 integrin Mac-1 on neutrophils. J Immunol (1998) 160(3):1427-35.

62. Fagerberg UL, Loof L, Merzoug RD, Hansson LO, Finkel Y. Fecal calprotectin levels in healthy children studied with an improved assay. JPediatr Gastroenterol Nutr (2003) 37(4):468-72. doi:10.1097/00005176-200310000-00013

63. Day AS, Ehn M, Gearry RB, Lemberg DA, Leach ST. Fecal S100A12 in healthy infants and children. Dis Markers (2013) 35(5):295-9. doi:10.1155/ $2013 / 873582$ 
64. Leach ST, Yang Z, Messina I, Song C, Geczy CL, Cunningham AM, et al. Serum and mucosal S100 proteins, calprotectin (S100A8/S100A9) and S100A12, are elevated at diagnosis in children with inflammatory bowel disease. Scand J Gastroenterol (2007) 42(11):1321-31. doi:10.1080/00365520701416709

65. Sidler MA, Leach ST, Day AS. Fecal S100A12 and fecal calprotectin as noninvasive markers for inflammatory bowel disease in children. Inflamm Bowel Dis (2008) 14(3):359-66. doi:10.1002/ibd.20336

66. D’Inca R, Dal Pont E, Di Leo V, Ferronato A, Fries W, Vettorato MG, et al. Calprotectin and lactoferrin in the assessment of intestinal inflammation and organic disease. Int J Colorectal Dis (2007) 22(4):429-37. doi:10.1007/s00384006-0159-9

67. Bunn SK, Bisset WM, Main MJ, Golden BE. Fecal calprotectin as a measure of disease activity in childhood inflammatory bowel disease. J Pediatr Gastroenterol Nutr (2001) 32(2):171-7. doi:10.1097/00005176-200102000-00015

68. Roseth AG, Aadland E, Jahnsen J, Raknerud N. Assessment of disease activity in ulcerative colitis by faecal calprotectin, a novel granulocyte marker protein. Digestion (1997) 58(2):176-80. doi:10.1159/000201441

69. Costa F, Mumolo MG, Bellini M, Romano MR, Ceccarelli L, Arpe P, et al. Role of faecal calprotectin as non-invasive marker of intestinal inflammation. Dig Liver Dis (2003) 35(9):642-7. doi:10.1016/S1590-8658(03)00381-5

70. Langhorst J, Elsenbruch S, Koelzer J, Rueffer A, Michalsen A, Dobos GJ. Noninvasive markers in the assessment of intestinal inflammation in inflammatory bowel diseases: performance of fecal lactoferrin, calprotectin, and PMNelastase, CRP, and clinical indices. Am J Gastroenterol (2008) 103(1):162-9. doi:10.1111/j.1572-0241.2007.01556.x

71. Bunn SK, Bisset WM, Main MJ, Gray ES, Olson S, Golden BE. Fecal calprotectin: validation as a noninvasive measure of bowel inflammation in childhood inflammatory bowel disease. J Pediatr Gastroenterol Nutr (2001) 33(1):14-22. doi:10.1097/00005176-200107000-00003

72. Tibble J, Teahon K, Thjodleifsson B, Roseth A, Sigthorsson G, Bridger S, et al. A simple method for assessing intestinal inflammation in Crohn's disease. Gut (2000) 47(4):506-13. doi:10.1136/gut.47.4.506

73. Sykora J, Siala K, Huml M, Varvarovska J, Schwarz J, Pomahacova R. Evaluation of faecal calprotectin as a valuable non-invasive marker in distinguishing gut pathogens in young children with acute gastroenteritis. Acta Paediatr (2010) 99(9):1389-95. doi:10.1111/j.1651-2227.2010.01843.x

74. Gisbert JP, McNicholl AG. Questions and answers on the role of faecal calprotectin as a biological marker in inflammatory bowel disease. Dig Liver Dis (2009) 41(1):56-66. doi:10.1016/j.dld.2008.05.008

75. Tibble JA, Sigthorsson G, Bridger S, Fagerhol MK, Bjarnason I. Surrogate markers of intestinal inflammation are predictive of relapse in patients with inflammatory bowel disease. Gastroenterology (2000) 119(1):15-22. doi:10.1053/gast. 2000.8523

76. Costa F, Mumolo MG, Ceccarelli L, Bellini M, Romano MR, Sterpi C, et al. Calprotectin is a stronger predictive marker of relapse in ulcerative colitis than in Crohn's disease. Gut (2005) 54(3):364-8. doi:10.1136/gut.2004.043406

77. de Jong NS, Leach ST, Day AS. Fecal S100A12: a novel noninvasive marker in children with Crohn's disease. Inflamm Bowel Dis (2006) 12(7):566-72. doi:10.1097/01.ibd.0000227626.72271.91

78. Werlin SL, Benuri-Silbiger I, Kerem E, Adler SN, Goldin E, Zimmerman J, et al. Evidence of intestinal inflammation in patients with cystic fibrosis. J Pediatr Gastroenterol Nutr (2010) 51(3):304-8. doi:10.1097/MPG.0b013e3181d1b013

79. Bruzzese E, Raia V, Gaudiello G, Polito G, Buccigrossi V, Formicola V, et al. Intestinal inflammation is a frequent feature of cystic fibrosis and is reduced by probiotic administration. Aliment Pharmacol Ther (2004) 20(7):813-9. doi:10.1111/j.1365-2036.2004.02174.x

80. Lisowska A, Madry E, Pogorzelski A, Szydlowski J, Radzikowski A, Walkowiak J. Small intestine bacterial overgrowth does not correspond to intestinal inflammation in cystic fibrosis. Scand J Clin Lab Invest (2010) 70(5):322-6. doi:10.3109/00365513.2010.486869

81. Ooi CY, Lee JM, Leach S, Katz T, Day AS, Jaffe A. Intestinal inflammation in CF: stool markers and correlation with pancreatic enzymes. J Cyst Fibros (2012) 11(S1):S114. doi:10.1016/S1569-1993(12)60395-6

82. Czub E, Herzig KH, Szaflarska-Popawska A, Kiehne K, Socha P, Wos H, et al. Fecal pyruvate kinase: a potential new marker for intestinal inflammation in children with inflammatory bowel disease. Scand J Gastroenterol (2007) 42(10):1147-50. doi:10.1080/00365520701320513

83. Chung-Faye G, Hayee B, Maestranzi S, Donaldson N, Forgacs I, Sherwood R. Fecal M2-pyruvate kinase (M2-PK): a novel marker of intestinal inflammation. Inflamm Bowel Dis (2007) 13(11):1374-8. doi:10.1002/ibd.20214
84. Judd TA, Day AS, Lemberg DA, Turner D, Leach ST. Update of fecal markers of inflammation in inflammatory bowel disease. J Gastroenterol Hepatol (2011) 26(10):1493-9. doi:10.1111/j.1440-1746.2011.06846.x

85. Hardt PD, Mazurek S, Toepler M, Schlierbach P, Bretzel RG, Eigenbrodt E, et al. Faecal tumour M2 pyruvate kinase: a new, sensitive screening tool for colorectal cancer. Br J Cancer (2004) 91(5):980-4. doi:10.1038/sj.bjc.6602033

86. Oehler R, Weingartmann G, Manhart N, Salzer U, Meissner M, Schlegel W, et al. Polytrauma induces increased expression of pyruvate kinase in neutrophils. Blood (2000) 95(3):1086-92.

87. McDowell G, Gupta S, Dellerba M, Coppinger T, Levy RD, Keevil BG. Plasma concentrations of tumour dimeric pyruvate kinase are increased in patients with chronic cardiac failure. Ann Clin Biochem (2004) 41(Pt 6):491-3. doi:10.1258/0004563042466712

88. Turner D, Leach ST, Mack D, Uusoue K, McLernon R, Hyams J, et al. Faecal calprotectin, lactoferrin, M2-pyruvate kinase and S100A12 in severe ulcerative colitis: a prospective multicentre comparison of predicting outcomes and monitoring response. Gut (2010) 59(9):1207-12. doi:10.1136/gut.2010. 211755

89. Walkowiak J, Banasiewicz T, Krokowicz P, Hansdorfer-Korzon R, Drews M, Herzig KH. Fecal pyruvate kinase (M2-PK): a new predictor for inflammation and severity of pouchitis. Scand J Gastroenterol (2005) 40(12):1493-4. doi:10.1080/00365520500319112

90. Johnson MW, Maestranzi S, Duffy AM, Dewar DH, Ciclitira PJ, Sherwood RA, et al. Faecal M2-pyruvate kinase: a novel, noninvasive marker of ileal pouch inflammation. Eur J Gastroenterol Hepatol (2009) 21(5):544-50. doi:10.1097/ MEG.0b013e3283040cb3

91. Roy CC, Kien CL, Bouthillier L, Levy E. Short-chain fatty acids: ready for prime time? Nutr Clin Pract (2006) 21(4):351-66. doi:10.1177/ 0115426506021004351

92. Forchielli ML, Walker WA. The role of gut-associated lymphoid tissues and mucosal defence. Br J Nutr (2005) 93(Suppl 1):S41-8. doi:10.1079/ BJN20041356

93. Canani RB, Costanzo MD, Leone L, Pedata M, Meli R, Calignano A. Potential beneficial effects of butyrate in intestinal and extraintestinal diseases. World J Gastroenterol (2011) 17(12):1519-28. doi:10.3748/wjg.v17.i12

94. Luhrs H, Gerke T, Muller JG, Melcher R, Schauber J, Boxberge F, et al. Butyrate inhibits NF-kappaB activation in lamina propria macrophages of patients with ulcerative colitis. Scand J Gastroenterol (2002) 37(4):458-66. doi:10.1080/003655202317316105

95. Segain JP, Raingeard de la Bletiere D, Bourreille A, Leray V, Gervois N, Rosales C, et al. Butyrate inhibits inflammatory responses through NFkappaB inhibition: implications for Crohn's disease. Gut (2000) 47(3):397-403. doi:10.1136/gut.47.3.397

96. Thibault R, Blachier F, Darcy-Vrillon B, de Coppet P, Bourreille A, Segain JP. Butyrate utilization by the colonic mucosa in inflammatory bowel diseases: a transport deficiency. Inflamm Bowel Dis (2010) 16(4):684-95. doi:10.1002/ ibd. 21108

97. Harig JM, Soergel KH, Komorowski RA, Wood CM. Treatment of diversion colitis with short-chain-fatty acid irrigation. N Engl J Med (1989) 320(1):23-8. doi:10.1056/NEJM198901053200105

98. Monira S, Hoq MM, Chowdhury AK, Suau A, Magne F, Endtz HP, et al. Shortchain fatty acids and commensal microbiota in the faeces of severely malnourished children with cholera rehydrated with three different carbohydrates. Eur J Clin Nutr (2010) 64(10):1116-24. doi:10.1038/ejcn.2010.123

99. Clausen MR, Bonnen H, Tvede M, Mortensen PB. Colonic fermentation to short-chain fatty acids is decreased in antibiotic-associated diarrhea. Gastroenterology (1991) 101(6):1497-504.

100. Vaisman N, Tabachnik E, Sklan D. Short-chain fatty acid absorption in patients with cystic fibrosis. J Pediatr Gastroenterol Nutr (1992) 15(2):146-9. doi:10.1097/00005176-199208000-00008

101. Owira PM, Winter TA. Colonic energy salvage in chronic pancreatic exocrine insufficiency. JPEN J Parenter Enteral Nutr (2008) 32(1):63-71. doi:10.1177/ 014860710803200163

102. Nguyen TD, Kim US, Perrine SP. Novel short chain fatty acids restore chloride secretion in cystic fibrosis. Biochem Biophys Res Commun (2006) 342(1):245-52. doi:10.1016/j.bbrc.2006.01.127

103. Torii T, Kanemitsu K, Wada T, Itoh S, Kinugawa K, Hagiwara A. Measurement of short-chain fatty acids in human faeces using high-performance liquid chromatography: specimen stability. Ann Clin Biochem (2010) 47(Pt 5):447-52. doi:10.1258/acb.2010.010047 
104. Pallen MJ, Loman NJ, Penn CW. High-throughput sequencing and clinical microbiology: progress, opportunities and challenges. Curr Opin Microbiol (2010) 13(5):625-31. doi:10.1016/j.mib.2010.08.003

Conflict of Interest Statement: The authors declare that the research was conducted in the absence of any commercial or financial relationships that could be construed as a potential conflict of interest.

Received: 27 November 2013; paper pending published: 16 December 2013; accepted: 12 January 2014; published online: 28 January 2014.
Citation: Pang T, Leach ST, Katz T, Day AS and Ooi CY (2014) Fecal biomarkers of intestinal health and disease in children. Front. Pediatr. 2:6. doi: 10.3389/fped.2014.00006

This article was submitted to Pediatric Gastroenterology and Hepatology, a section of the journal Frontiers in Pediatrics.

Copyright (c) 2014 Pang, Leach, Katz, Day and Ooi. This is an open-access article distributed under the terms of the Creative Commons Attribution License (CC BY). The use, distribution or reproduction in other forums is permitted, provided the original author(s) or licensor are credited and that the original publication in this journal is cited, in accordance with accepted academic practice. No use, distribution or reproduction is permitted which does not comply with these terms. 